Portland State University

PDXScholar

\title{
A demographic study based upon income, age and education variables as related to the willingness or unwillingness to accept foster children
}

John Hughes

Portland State University

Linda A. Kaeser

Susan E. Norman

Lillian Rinderknecht

John Wills

Follow this and additional works at: https://pdxscholar.library.pdx.edu/open_access_etds

Part of the Social Work Commons

Let us know how access to this document benefits you.

\section{Recommended Citation}

Hughes, John; Kaeser, Linda A.; Norman, Susan E.; Rinderknecht, Lillian; and Wills, John, "A demographic study based upon income, age and education variables as related to the willingness or unwillingness to accept foster children" (1970). Dissertations and Theses. Paper 656.

https://doi.org/10.15760/etd.656

This Thesis is brought to you for free and open access. It has been accepted for inclusion in Dissertations and Theses by an authorized administrator of PDXScholar. Please contact us if we can make this document more accessible: pdxscholar@pdx.edu. 
AN ABSTRACT OF THE THESIS OF John Hughes, et al. for the Master of Social Work presented May 20, 1970.

Title: A Demographic Study Based Upon Income, Age and Education Variables as Related to the Willingness or Unwillingness to Accept Foster Children.

\section{APPROVED BY MEMBERS OF THE THESIS COMMITTEE:}
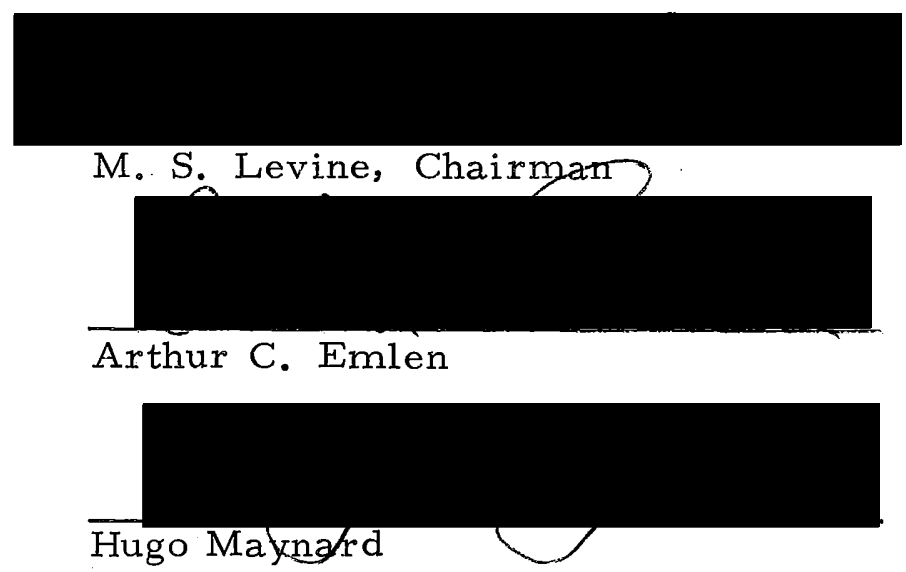

The research problem in this thesis can be briefly stated as a study of a general population to test certain demographic variables, in particular those of income, age and education, which may or may not have a significant relationship to an expressed willingness to care for foster children; and to further examine whether certain special characteristics of a child, in particular those of increased age, physical handicap, minor emotional problems or mental 
retardation, further increase unwillingness to care for foster children.

The sample was selected by a two-stage cluster sampling taken from the Southeast catchment area of metropolitan Portland, Oregon. From this sample of 787 individuals, the survey was conducted by trained interviewers, using a questionnaire and personal interview. The data used in this research project were then extracted from the larger survey and computed to determine the relationship of age, income and education to willingness to care for foster children. The data were extracted on the basis of the chosen variables of income, age and education and five questions relating specifically to willingness to care for foster children.

As had been anticipated, the findings showed that the general population is not willing to care for foster children. However, certain significant findings were related to willingness to care for foster children. A significant relationship was found between income and willingness to care for foster children in that those respondents with incomes between $\$ 4,000-\$ 20,000$ expressed the most willingness to care for foster children while there was significant underrepresentation in both the highest and lowest income groupings to express a willingness to care for foster children with an almost lineal relationship of decreasing age with increasing willingness to care for foster children. There is no significant relationship, it was found, between 
education of the respondent and willingness to care for foster children. There is a lineal relationship of increasing willingness to care for foster children with increasing age of the foster child. Of those individuals expressing a willingness to care for foster children, there is no significant decrease in willingness because of physical disability, minor emotional problems or mental retardation.

The results of this study have certain implication for recruitment and selection of foster parents. The findings indicate the need for further research to explore why more individuals in the population do not express a willingness to care for foster children, how such an interest can be encouraged and what criteria can be used in recruitment and selection. 
A DEMOGRAPHIC STUDY BASED UPON INCOME, AGE AND EDUCATION VARIABLES AS RELATED TO THE WILLINGNESS OR UNWILLINGNESS TO ACCEPT FOSTER CHILDREN

by:

JOHN HUGHES

LINDA A. KAESER
SUSAN E. NORMAN

LILLIAN RINDERKNECHT

JOHN WILLS

A thesis submitted in partial fulfillment of the

requirements for the degree of

MASTER OF SOCIAL WORK

Portland State University

1970 
TO THE OFFICE OF GRADUATE STUDIES:

The members of the Committee approve the thesis of

John Hughes, et al. presented May 20, 1970.

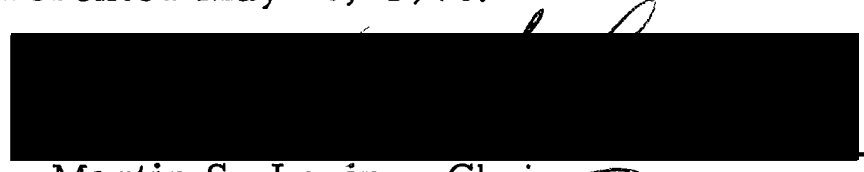

Martin S. Levine, Ghairmany

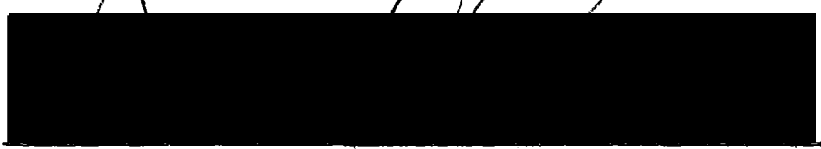

Arthur C. Emlen

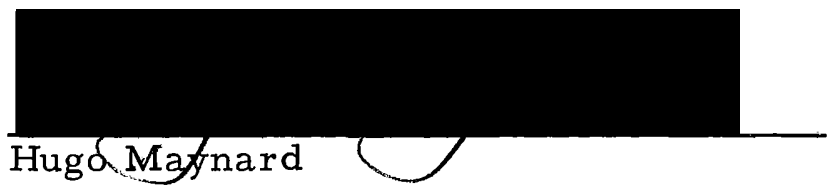

APPROVED:

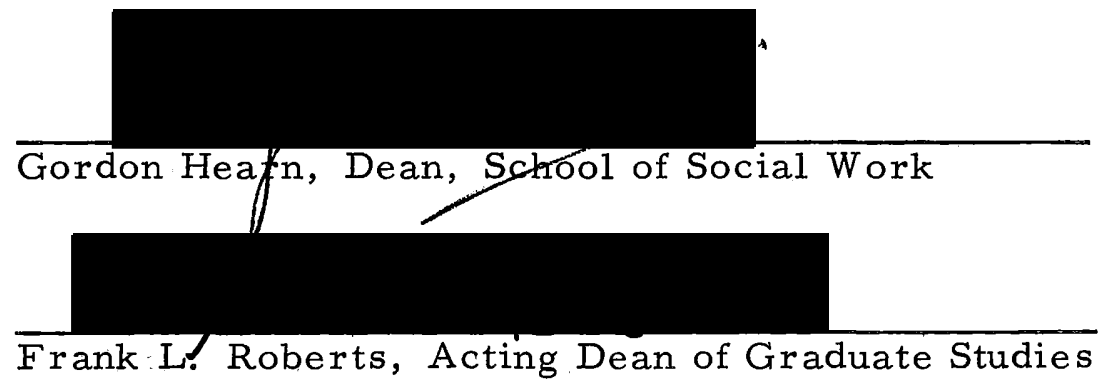

May 22, 1970 


\section{A CKNOW LEDGMENT}

To M. S. Levine. . he opened the doors. 
TABLE OF CONTENTS

PAGE

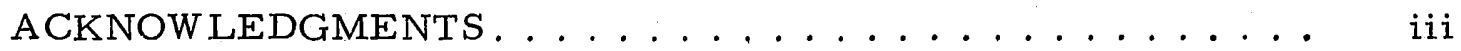

LIST OF TABLES ..................... v v

CHAPTER

I INTRODUCTION ................. 1

Brief History of Foster Care in

the United States........... 3

A Review of Pertinent Literature ...... 6

Purpose of Study....................... 14

II DESCRIPTION AND OBJECTIVES OF

CURRENT STUDY .................. 18

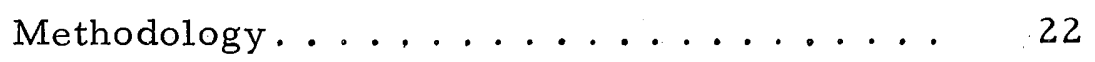

III RESULTS OF THE STUDY .............. 28

Characteristics of the Population Sample . . 28

IV DISCUSSION OF FINDINGS ............ 44

Expressed Willingness Versus Actual

Foster Care.............. 46

Representativeness of the Sample . . . . 47

Characteristics of Potential Foster

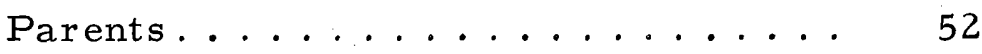

Selection of Foster Parents 53 
V SUMMARY AND CONCLUSIONS ......... 57

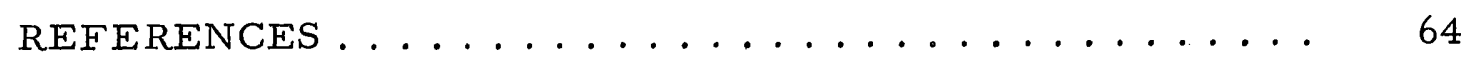




\section{LIST OF TABLES}

TABLE

PAGE

I General Form of Survey Data ........... 26

II Willingness to Take Care of Foster Children.... 30

III Age of Foster Child Most Willing to Accept. . . . 31

IV Willingness to Care for Foster Children with a

Noticeable Physical Disability. .........

V Willingness to Care for a Foster Child with

Relatively Minor Emotional Problems ......

VI Willingness to Care for a Foster Child Who

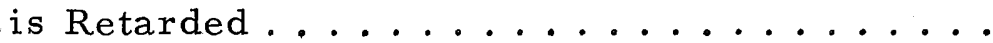

VII Attitudes Toward Care of Foster Children

According to Income .............

VIII Income to Attitude Toward Care of Foster

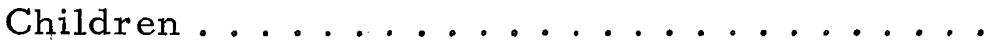

IX Attitudes Toward Care of Foster Children

According to Age of Respondents ...... 36

$\mathrm{X} \quad$ Age to Attitude Toward Care of Foster Children ..

XI Attitude Toward Care of Foster Children

According to Educational Level of

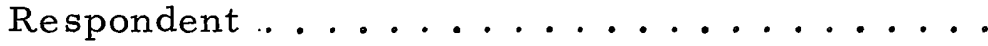


TABLE

XII Education to Attitude Toward Care of Foster

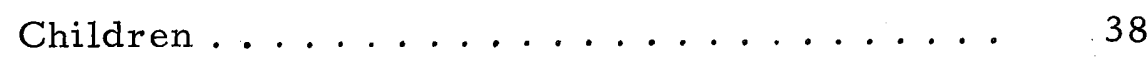

XIII Comparison of Means for Income to Attitude . . . . 40

XIV Means for Education Groupings .......... 41

XV Comparison of Means for Age to Attitude Using

Tukey $(a) \ldots \ldots \ldots \ldots \ldots$

XVI Comparison of Income Distribution for Mental

Health Survey and 1960 Census for S. E.

Portland Catchment Area........... 48

XVII Survey: Educational Level Compared to 1960

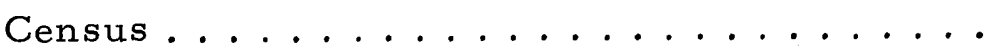

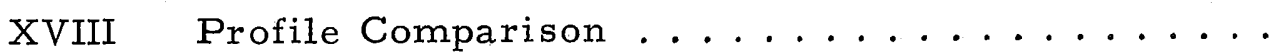




\section{CHAPTER I}

\section{INTRODUCTION}

One of the most critical is sues in child welfare today is the development of an adequate foster parenthood program.

The problems of foster parenthood, as detailed in a review of the literature, are both complex and, many times contradictory.

The criteria for selecting foster parents are as vaguely defined today as they: were in the early 1940's. The implications of the selection criteria problem have been stated by Taylor and Star $r$ :

The last 15 years have been a period in which foster family care has replaced the custodial institution as the placement of choice for large numbers of children, and there are increasing demands for foster parents to serve in specialized programs for emotionally disturbed and retarded children.

The supply of prospective foster parents apparently has been reduced as a result of such factors as the increasing number of families living and working in cities where smaller homes are the rule, greater family geographic and social mobility and the deemphasis of the social utility of the maternal and homemaking roles of women. 1

Needless to say, foster parenthood is a very delicate undertaking, "both from the administrative, and perhaps even more,

IDelores A. Taylor and Philip Starr, "Foster Parenting: An Integrative Review of the Literature, " Child Welfare, XLVI (July, 1967), 376. 
from the psychological point of view. $"{ }^{2}$

As Dinnage summarizes:

There is much more uncertainty and impermanence than in adoption; and there is a closer, more intimate personal involvement than in residential care of various kinds. The complexity arises partly from the rather ill-defined roles and relationships of all those most closely involved in the fostering situation; the child who is being placed; his parents; the foster parents; and the placing agency's caseworker.

The foster parents who, quite literally, stand in loco parentis, must yet prevent themselves from wishing to assume all parental functions; these remain in the prerogative of the child's own parents, or else have been temporarily transferred to the child care agency. . . moreover, while willingness to give affection is essential, this must not become too exclusive or possessive, since the relationship with the foster child is likely to be, or at least must be assumed to be, temporary. 3

It is estimated that approximately 250,000 children in the

United States presently live in foster homes. Since the average

length of stay is less than two years, it has been projected that more than $1,800,000$ children in today's generation will reside in foster homes during some period of their childhood. ${ }^{4}$ : As Joseph Reid, executive director of the Child Welfare League in America in 1963, pointed out:

${ }^{2}$ Rosemary Dinnage and M. L. Kellmer Pringle, Foster Home Care Facts and Fallacies (London: Longmans, 1967), p. 27.

3 Ibid.

${ }^{4}$ Joseph Reid, (Author of the) "Foreword," in Selecting Foster Parents by Martin Wolins, (New York: Columbia: University Press, 1963). 
More than $\$ 300$ million will be expended each year to sus tain them (foster children) in their foster homes. Whether this money is well spent or wasted will depend on how well the general public and professional social workers understand the role and function of foster care. 5

The plight of children in substitute care situations, including adoptions and institutional care as well as foster care, was described in a large-scale investigation of nine American communities by Maas and Engler. As a result of the study, the Child Welfare League of America made numerous far-reaching recommendations, including improved preventive services, counseling services, research and better use of publicity and advertising for educating the general public regarding substitute care. 6

\section{BRIEF HISTORY OF FOSTER CARE IN THE UNITED STATES}

The gradual evolvement of foster family care as we understand it today, and the changed status of the child from an investment to a person of social being came about in both England and America during the latter half of the 19th Century.

Public officials had placed children with families as early as the middle of the 17 th Century, but the so-called chattel emphasis

\section{${ }^{5}$ Ibid.}

${ }^{6}$ Henry: Maas and Richard Enger, Children in Need of Parents (New York: Columbia University Press, 1959), pp. 379-97. 
remained prevalent for nearly 200 years. Even Charles Loring Brace, who is credited with launching the American foster care movement in the $1850^{\prime}$ s could not totally abandon the link between foster care and property contractual arrangements. 7

Brace's organization, the Children's Aid Society, however, was primarily committed to placement with little or no emphasis on continuous involvement with foster families and the placed child. There was a tendency by Brace and his co-workers to consider foster care as a permanent arrangement.

It was not long before the methods of the Children's Aid Society came under attack. In 1884, Hastings Hart revealed the serious problems of foster care placement in the United States in a report to the Committee on Child-Saving Work of the National Conference of Charities and Corrections. Hart severely criticized the lack of agency follow-up procedures after placement, and the process of selecting foster homes and as signing children to them. 8

Charles W. Birtwell, who served as an outdoor worker for the Boston Children's Aid Society during the 1890's, noted in the society's annual report during that period:

${ }^{7}$ Robert H. Bremmer, American Philanthropy, (Chicago: University of Chicago Press, 1960), pp. 63-4.

${ }^{8}$ Martin Wolins, Selecting Foster Parents (New York: Columbia University Press, 1963), p. 11 . 
. . these children cannot be divorced from the natural relations of family life without loss, anymore than can those born under more favorable conditions, and therefore we must - . learn the ways in which family ties may be strengthened and parental responsibilities maintained while working at the same time for the reformation of the child. 9

It was Birtwell, according to some historians and researchers, who was among the first to have "abstracted the essence of modern foster family care. . (gradually) the functions of parents and foster parents have diverged as concessions to the child's own family and social agency. $" 10$

But even today, the problems of foster parenthood remain numerous.

The role of the foster parent is not clear by any means. He is neither parent nor agency staff member. The foster parent, often burdened with many obligations and few rewards or privileges, is hard to recruit and difficult to select and keep.

There is an abundance of clinical and empirical data in the foster care literature, but, as noted earlier, it is replete with duplications and contradictions. For instance, there appears to be a lack of agreement on the part of researchers regarding the demographic characteristics of foster parents. ${ }^{11}$

Another indication of the inconsistency within research findings are the studies of foster parent motivational factors. Taylor
${ }^{9}$ Ibid.
$10^{1 \text { Ibid. }}$
${ }^{11}$ Ibid. , p. 377. 
and Starr state that such research "rests on the assumption that there is a relationship between the motivation and adequacy of performance. 12 The validity of such an assumption has been seriously challenged by numerous researchers.

\section{A REVIEW OF PERTINENT LITERATURE}

There is general agreement in the literature regarding the purposed aims of foster care.

The goals of foster care have been summaried by the Child Welfare League of America in its Standards for Foster Care Service:

The ultimate objectives . . . should be the promotion of healthy personality development of the child, and the amelioration of problems that are personally or socially destructive. . . Foster family care should provide for the child whose parents cannot do so, experience and conditions which promote normal maturation (care), which prevent injury to the child (protection), and which correct specific problems which interfere with personality development (treatment). ${ }^{13}$

Whether these objectives are being met is unknown.

The reason, clearly, is a lack of data and research on foster parenthood.

In 1966, David Fanshel declared:

Considering the number of children exposed to the experience of foster care, the paucity of basic data on all aspects of foster home care is surprising. One searches in vain in the literature of child welfare practitioners for well-conceived theoretical formulations about the nature of foster parenthood.
12 Ibid. , p. 376.
${ }^{13}$ Dinnage and Pringle, p. 27. 
What one does find is a few reports of studies of limited scope along with a good deal of thoughtful reflection by caseworkers on the character and problems of foster parents. 14

Rosemary Dinnage came to the same conclusion when she stated, "Research workers have not been over-eager to study foster care. . . During the 18-year period under review, there have been only six large-scale, well-designed studies. " ${ }^{15}$ The first she cites was by Soule, et al. in 1962. The French study was followed by two in the United States, by Wolins in 1963 and Fanshel in 1966. The other three major studies were conducted in Great Britian, by Gray and Parr in 1957, Trasler in 1960 and Parker in 1966.

For the purposes of this study, we will briefly outline the major findings in the above-mentioned foreign research projects.

1. Gray and Parr: The purpose of the study was an inquiry into the characteristics of foster parents. The major findings:

Fifty-nine per cent of foster mothers were over 40 when recruited . . . highest and lowest income groups were underrepresented.

Own children: 49 per cent had no children of their own living with them. . . 12 per cent had adopted children . . . 36 per cent were childless. Twenty-two per cent were hoping to adopt their foster children.

When they were asked what they thought stopped people (from) taking foster children, 37 per cent said fear of how the child would turn out; 19 per cent said fear of losing the child after becoming fond of it; 29 per cent would not (take another foster child.

${ }^{14}$ Ibid. , p. $27 . \quad{ }^{15}$ Ibid. , p. 29. 
Twice as many foster mothers had wanted girls as boys, but some had been persuaded to take boys. There was a preference for younger children; although 40 per cent of children in homes are over 11 , only 5 per cent of foster mothers preferred that age group. 16

2. Trasler: This study attempted to uncover various motivational factors of individuals seeking to become foster parents. The finding s:

Some foster parents seek a child who will be a companion, either to one of their own children or because they themselves are lonely.

Foster parents sometimes feel they are "doing good" when they board children. 17

3. Soule, et al. : This study is a detailed review of foster care in France. The findings:

Age of foster mothers: 20-35, 29 per cent; 36-50, 49 per cent; $51-60,18$ per cent; over 60,3 per cent.

Sixty-two per cent of the foster fathers were skilled workmen, 12 per cent came from modest rural backgrounds.. . . 3.5 per cent had higher socio-economic status.

Fifty-two per cent of foster mothers had grown-up children, 26 per cent young children, 22 per cent no children. 18

4. Parker: This was a study of foster placements from case records in order to attempt to predict the probable long-term

\section{Ibid. , p. 103.}

17 Gordon Trasler, In Place of Parents (London: Routledge and Kegen Paul, 1960), pp. $1 \overline{15-80 .}$

${ }^{18}$ Dinnage and Pringle, pp. 139-40. 
success or failure of future placements. The findings:

The presence of foster parents' own children in the home was significantly associated with failure, especially if they were very young or close to the foster child in age. The presence of own siblings or of other foster children did not affect success or failure.

The lower the socio-economic class of foster parents, the more likelihood there was of the placement being successful.

There was a slight association between success and increasing age of the foster mother, in spite of the fact that older foster mothers tended to take older children (who failed more often than younger children).

Childless couples were more successful than those with children.

The small number of homes without a foster father was averagely successful. 19

Although this study is not concerned primarily with the motivational factors regarding foster parenthood, an extensive amount of literature is devoted to this topic. A review of the literature, therefore, would be incomplete without acknowledging the efforts of such researchers as Fanshel, who produced one of the most comprehensive studies on the motivations and role of foster parents in the early 1960's. 20

Most investigators, however, display a certain amount of

19

Ibid. , pp. 172-3.

20 David Fanshe1, Foster Parenthood: A Role Analysis (Minneapolis: University of Minnesota Press, 1966), pp. 1-176. 
caution when attempting to determine the motivations of foster

parents. Dinnage, for instance, states:

Investigation of motivations must depend a great deal on the author's interpretation of his material, not only because questions about motives are always hard to answer, but because foster parents . . are not generally an articulate group. It may safely be inferred that there are women who foster children because it "comes naturally" and those who foster to fill a special gap, and that the two groups may overlap and shade into each other. 21

Taylor and Starr in their review of foster parenthood literature came to basically the same conclusion.

A number of clinical writers agree that motivations as expressed by prospective foster parents should be considered only as a starting point for the exploration of deeper motives. They agree that a common fallacy to avoid is the idea that to know a motive is to know the outcome of a course of action. Instead, the assessment of foster parent motivation should result in an understanding of how the motives will be expressed in the foster parent-child relationship. 22

As noted earlier, there is a great discrepancy in the findings of descriptive studies on the demographic characteristics of foster parents.

Charlotte Babcock produced what has been described as an impressionistic profile of the typical American fostering couples based upon detailed case record examinations of 25 foster couples. She concluded:

Each of the 50 foster parents in the study came from fairly large families with minimal educational and work-income levels.
21 Ibid., p. 20.
${ }^{22}$ Taylor and Starr, p. 377. 
Most married spouses from their own childhood area before the age of 20 .

The foster parents received a great deal of satisfaction from children, especially infants.

Except for kinship ties, the foster parents remained fairly isolated from the community and settled in semi-rural or rural areas. 23

In Part II of her extensive study, Babcock focused on the relationships between the 25 foster couples. 24

Foster couples studied by Wakeford were somewhat similar in that they had few interests outside their own home and family, and the foster parents wanted large families. 25

A study by DeFries produced the following findings:

A majority of foster mothers and foster fathers came from a segment of the population with minimal educational and income levels.

Fewer than one-half of the foster parents under study completed high school.

The foster parents tended to be older than most natural parents . . "in many instances were more like grandparents.. the median age was just over 50.1126

${ }^{23}$ Charlotte Babcock, "Some Psychodynamic Factors in Foster Parenthood-Part I," Child Welfare, XLIV (1965), 485-93.

${ }^{24}$ Charlotte Babcock, "Some Psychodynamic Factors in Foster Parenthood-Part II, "Child Welfare, XLIV (1965), 570-77.

${ }^{25}$ Dinnage and Pringle, pp. 140-1.

${ }^{26}$ Zira DeFries, et al., "Foster Care for Disturbed Children --A Nonsentimental View," Child Welfare, XLIV (1965), 73-84. 
Rich, in a study of parents in 22 foster homes, concluded:

Most foster parents, upon application "were already a:well established family unit, not young couples striving to be established."

The (foster) family income "had about reached its peak."

The majority of foster fathers were in skilled or semiskilled occupations and earned between four to six thousand dollars.

Foster mothers had slightly better education than foster fathers, but few had gone beyond the 10th grade. 27

Albinder found that foster parents had lower verbal and reading abilities, most below ninth and tenth grade levels. 28

Despite the findings of Babcock, Wakeford, DeFries and Rich, a metropolitan, tri-county survey by Glassberg in the Philadelphia area found that foster couple applicants were significantly representative of the total population as far as race, income and religion factors were concerned. Albinder's study showed:

Approximately 73 per cent of the applicants were white and 27 per cent were Negro couples. The tri-county population figures in 1960 showed that 85 per cent of the total population were white families and 15 per cent were non-white families.

Of the applicants, 63.6 per cent were Protestants, 32. 1 per cent Catholic and 4.2 per cent Jewish. The tri-county area had a religion population divided as follows: Protestant 64. 2, Catholic 34. 7, Jewish 10.7.

27 Mabel Rich, "Foster Homes for Retarded Children," Child Welfare, XLIV (1965), 392-4.

${ }^{28}$ Dinnage and Pringle, p. 377. 
There was no significant difference regarding the median income between applicants and the general population of the Philadelphia metropolitan area.

Approximately 40 per cent of the applicant families had incomes above $\$ 6,000$ and 20 per cent had incomes above $\$ 8,000.29$

In his extensive research project on foster parenthood, Wolins described a number of demographic characteristics relating to fostering couples. Wolins' findings were in four categories: race, religion, childhood residence and education. His data showed the following results:

Foster families are geographically: stable. Approximately 95 per cent lived in the same neighborhood for one year or more; nearly 65 per cent had lived in the same neighborhood for more than five years.

Most foster parents "clustered heavily" in the 40-and-over age group.

Foster families are modally like the general population of the counties under study. For instance, foster parents are predominantly Caucasian (80 per cent), Protestant (61 per cent), urban-reared (62 per cent), high school graduates (61 per cent) and craft-or factory-employed fathers (58 per cent). 30

${ }^{29}$ Eudice Glassberg, "Are Foster Homes Hard to Find?" Child Welfare, XLIV (1965), 453-60.

${ }^{30}$ Wolins, pp. 115-6. 


\section{PURPOSE OF STUDY}

This thesis project will be a descriptive study describing and relating demographic characteristics to an individual respondent's statement of willingness or unwillingness to accept foster children. The study is based upon and is part of an extensive sample survey of metropolitan Southeast Portland. 31

The sample survey methodology was intended to allow for a more in-depth approach to study certain demographic variables and their relationship to attitudes toward foster child care.

The demographic variables considered are age, income and education of the respondents as well as respondent answers to a series of questions on foster child care. The survey questionnaire of 105 items covered a total of seven areas as follows:

1. Demographic variables

Age

Income

Education

Work

Family composition

${ }^{31}$ M. S. Levine, Proposal for Evaluation of Need, Use and Impact of Mental Health Services and Related Resources on Southeast Catchment Area of Portland, Report to Oregon State Division of Mental Health, (Salem, Oregon: Oregon State Division of Mental Health, 1968), June, 1968. 
2. Other social, psychological and economic variables pertinent to community mental health

Physical and social mobility

Marital status (past and present)

Medical insurance

Religious membership

Veteran status

Physical health

3. Attitudes toward mental health

4. Expressed individual and family mental health needs

5. Actual individual and family mental health needs

6. Resource usages

7. Extent of community involvement

The survey used a two-stage, cluster sample collected by the following procedure: First, using a large and up-to-date city block map of the area to be sampled, each block was serially numbered in serpentine fashion; that is, starting at the upper right hand corner of the map and then numbering the blocks in an inward, spiraling, and counter-clockwise direction. Second, the random sample of 600 blocks was drawn, with each selected block receiving a consecutive code number. Third, each of the 600 blocks was individually diagrammed showing the dwelling units constituting each block. A surplus of 200 blocks were drawn because it was anticipated that a 
certain number of the selected blocks would contain only businesses rather than dwelling units and thus would require replacement.

The second stage of the cluster sampling involved the following procedures: First, sampling 800 dwelling units from 400 blocks resulted in an average of two dwelling units per selected block. Second, since the blocks vary in the number of dwelling units contained in each, a constant percentage rather than a constant number of dwelling units was drawn from each block. A total of 787 individuals of the 800 interviewees originally planned were actually interviewed.

Of the 105 items in the Southeast Portland survey a total of eight questions were used for this study of attitudes toward foster child care. The specific questions used in this study are as follows: ${ }^{32}$

\section{Section 7}

Question 15. Would you be willing to take care of foster children?

IF YES TO 15, ASK THE FOLLOWING QUESTIONS THROUGH 19.

Question 16. What age foster children would you be willing most to take care of?

Question 17. Would you be willing to take care of a foster child with a noticeable physical disability?

32 Oregon State Division of Mental Health, "S. E. Portland Mental Health Survey," Salem, 1969. (Mimeographed.) 
Question 18. Would you be willing to take care of a foster child with relatively minor emotional problems?

Question 19. Would you be willing to take care of a foster child who is retarded?

To obtain demographic data on age, income and education of respondents, the following questions were asked:

\section{Section 6}

Question 41. Here is another card. Would you please point to the group where your total family income fell last year? I mean what everybody gets.

$$
\begin{aligned}
& \$ 20,000 \text { and over } \\
& \$ 15,000 \text { to } 19,999 \\
& \$ 10,000 \text { to } 14,999 \\
& 7,000 \text { to } 9,999 \\
& 5,000 \text { to } 6,999 \\
& 4,000 \text { to } 4,999 \\
& 3,000 \text { to } 3,999 \\
& \text { Less than } \$ 3,000
\end{aligned}
$$

Section 2

Question 2. Age of the respondent?

$\begin{array}{ll}\text { Teen's } & 50^{\prime} \mathrm{s} \\ 20^{\prime} \mathrm{s} & 60^{\prime} \mathrm{s} \\ 30^{\prime} \mathrm{s} & 70^{\prime} \mathrm{s} \\ 40^{\prime} \mathrm{s} & 80^{\prime} \mathrm{s}\end{array}$

Question 4. How much schooling for the respondent?

5 or less

6 to 8

9 to 11

High school graduate

Trade or Beauty School

Some college

Bachelor's Degree

Graduate Training 


\section{CHAPTER II}

\section{DESCRIPTION AND OBJECTIVES OF CURRENT STUDY}

In reviewing the literature and research data, the majority of which has been conducted with individuals who already are caring for foster children, it was discovered that there are significant differences in findings on demographic characteristics of these individuals.

However, some characteristics appear to have greater support than others from available studies. For example, it has been noted that foster parents are drawn primarily from the lower socioeconomic classes and it appears that foster parents tend to have minimum incomes, clustering in the $\$ 4,000-6,000 \mathrm{range}^{1}$ Some researchers discovered that most foster parents do not complete high school, ${ }^{2}$ and ages of foster parents generally appear to fall between the ages of 35 and $50 .^{3}$

On the basis of the literature, it is reasonable to as sume that a study based on the sample survey methodology would support the

${ }^{1}$ DeFries, pp. 73-84; Rich, pp. 392-4.

220Fries, pp. 73-84; Rich, pp. 392-4; Babcock, pp. 485-93.

${ }^{3}$ DeFries, pp. 73-84; Dinnage and Pringle, pp. 127, 139-40. 
following as sumptions:

Hypothesis I. Demographic factors of income, education and age are related to an individual's willingness to care for foster children.

Hypothesis IIa. As income increases there will be less of a tendency on the part of individuals to express willingness to care for foster children.

Hypothesis IIb. The inverse of IIa is that is that individuals at low income levels (below the $\$ 6,000$ range) will indicate a greater willingness to care for foster children than individuals at any other income level.

Hypothesis IIIa. As education increases there will be less of a tendency on the part of individuals to express willingness to care for foster children.

Hypothesis IIIb. The inverse of IIIa is that individuals with less than a high school education will indicate a greater willingness to care for foster children than individuals with more than a high school education.

Hypothesis IV. Middle-age respondents between the ages of 35 and 50 show a greater tendency to care for foster children than any other age grouping.

In terms of the questionnaire results, Hypotheses I through:IV would be tested by the following outcomes. 
Hypothesis I. The questions on income (Section 6, question 41), education (Section 2, question 4) and age (Section 2, question 2) will show a significant relationship to the responses to question 15 , Section 7, which relates to an individual's willingness to take care of foster children.

Hypothesis II. Responses to the income question which is question 41 , Section 6 , will show a significant relationship to question 15 , Section 7 , which is the question relating to willingness to take care of foster children.

Hypothesis III. Responses to the education question which is question 4, Section 2, will show a significant relationship to the foster care question 15, Section 7.

Hypothesis IV. Responses to the age question, question 2, Section 2, will show a significant relationship to the foster care question 15, Section 7.

In regard to those questions dealing with willingness to take care of a foster child, and the relation of this willingness or unwillingness to the unique characteristics of foster children, the following hypotheses are based on the literature and reports from the field.

Hypothesis V. Individuals (respondents) are more likely not to be willing to take care of foster children.

Hypothesis VI. As the age of foster children increases individuals (respondents) are less willing to take care of them. 
Hypothesis VII. Individuals are less willing to take care of foster children with a noticeable physical disability than children without a noticeable physical disability.

Hypothesis VIII. Individuals are less willing to take care of foster children with relatively minor emotional problems than for children without minor emotional problems.

Hypothesis IX. Individuals are less willing to take care of foster children who are retarded than for children who are not retarded.

In terms of questionnaire results, Hypotheses V through IX would be tested by the following outcomes:

Hypothesis V. Responses to question 15, Section 7, relating to the willingness to take care of foster children will show that more individuals will answer no, than yes or maybe.

Hypothesis VI. Responses to question 16, Section 7 will show that as the age of the foster children increases, individuals (respondents) are less willing to take care of them.

Hypothesis VII. Responses to question 17, Section 7 relating to the willingness to take care of a foster child with a noticeable physical disability will show that more individuals will answer no, than yes or maybe, and that more individuals will answer maybe than yes.

Hypothesis VIII. Responses to question 18, Section 7 relating to the willingness to take care of a foster child with relatively minor 
emotional problems will show that more individuals will answer no, than yes or maybe, and that more individuals will answer maybe than yes.

Hypothesis IX. Responses to question 19, Section 7 relating to willingness to take care of a foster child who is retarded will show that more individuals will answer no, than yes or maybe, and that more individuals will answer maybe than yes.

\section{METHODOLOGY}

The method or study design consists of two steps in analyzing the results. One is the sample survey results; 4 and the other is the use of statistical procedures including. Analysis of Variance, Single Factor Design, ${ }^{5}$ and the use of $Z$ scores in further refinement of the data. 6

By prior decision our population was fixed. It was the Southeast (S. E.) catchment area of Portland, an area which holds approximately one-third of metropolitan Portland and has a population of

${ }^{4}$ Morris Hanson, William Hurwitz and William Madow, Sample Survey Method and Theory (New York: John Wiley and Son, 1953).

${ }^{5}$ B. J. Winer, Statistical Principles in Experimental Design (New York: McGraw-Hill, 1962), pp. 44-104.

${ }^{6}$ H. M. Blalock, Social Statistics (New York: McGraw-Hill, 1960), pp. 176-9. 
170, 000. This area, according to the 1960 Census, is a representative cross section of Portland, with the exception of a small proportion of Negroes and the very highest socio-economic level.

The survey sample decided upon was 800 dwelling units. ${ }^{7}$ The reason for the 800 figure was the size of the grant available, the extent of the interviewing problem in time, money and extensiveness of the interview. Another, equally if not most important, factor was the need to sample enough respondents who had used mental health resources (clinics and hospitals). The number of users was estimated at 10 per cent of the S. E. Portland population. This would provide a proportional sample of 80 respondents out of 800 who had used mental health resources.

To obtain a sample of 800 dwelling units, a two-stage cluster sampling design was employed. A dwelling unit refers to a single, presently occupied residence such as a house, one unit of a duplex or a single apartment in an apartment building. The first stage of the cluster sampling, the goal of which was to obtain a random sample of 400 city blocks, involved the following procedures: First, using a large and up-to-date city, block map of the area to be sampled, each block was serially numbered in serpentine fashion, that is, starting at the upper right hand corner of the map and then

\footnotetext{
7 Levine, p. 120 .
} 
numbering the blocks in an inward, spiraling and counter-clockwise direction. Second, the random sample of 600 blocks was drawn, with each selected block receiving a consecutive code number. Thus each selected block had a code number that fell within the 1 to 600 number range. A surplus 200 blocks were drawn because it was anticipated that a certain number of the selected blocks would contain only. businesses rather than dwelling units and thus would require replacement. Third, each of the 600 blocks was individually diagrammed showing the dwelling units constituting each block. These three steps provided a random sample of 600 blocks, with a relatively complete and up-to-date listing of the dwelling units within each block.

The second stage of the cluster sampling, the goal of which was to obtain a random sample of 800 dwelling units from the previously selected 400 blocks, was to involve the following procedures: First, sampling 800 dwelling units from 400 blocks resulted in an average of two dwelling units per selected block. Second, since the blocks vary in the number of dwelling units contained in each, a constant percentage rather than a constant number of dwelling units was drawn from each block. This procedure reduces error variance by keeping the probability of a dwelling unit being selected constant, regardless of the number of dwelling units in the block. Third, an excess number of dwelling units were drawn from each block to 
provide a surplus for replacement due to such factors as no occupancy, erroneous listing of a dwelling unit, inability to contact a resident of the dwelling unit, etc.

Statistical treatment of the data, which were key punched and programmed for the Honeywell, 1200 Series Computer, for testing the significance of the relationship of the demographic variables-income, education and age--to attitude toward care of foster children, was by Analysis of Variance, using a single factor design.

The rationale for using. Analysis of Variance, was that it would allow for post hoc comparisons of means based on an overall test of significance involving means. The design of single factor experiments is a special case of completely randomized design, and considering the kinds of biases that might have been introduced into the collection of the data the survey data would depart from the criteria of "complete randomization. " 8 Also two-stage cluster sampling introduces sampling biases as contrasted to a sample survey design based on a simple (complete) random sample. However, the Analysis of Variance test is robust in regards to departure from homogeneity in each of the population groupings sampled. Where variances do depart from homogeneity then $F$ tends in a slightly more positive direction.

${ }^{8}$ Winer, p. 47. 
The data used in this study are selected from a much larger source in which innumerable comparisons between demographic and other variables can be made. In interpreting the results, the decision was made to use a. 01 level of significance.

TABLE I

GENERAL FORM OF SUMMARY DATA

\begin{tabular}{lcccc}
\hline \multicolumn{1}{c}{ Source } & SS & $\mathrm{df}$ & MS & $F$ \\
\hline & & & \\
Methods & SS Method & $\mathrm{K}-1$ & MS Method & $\mathrm{F}=\frac{\text { MS Method }}{\text { MS Error }}$ \\
$\begin{array}{l}\text { Experimental } \\
\text { error }\end{array}$ & SS Error & $\mathrm{kn}-\mathrm{K}$ & MS Error \\
Total & SST & $\mathrm{kn}-1$ & \\
\hline
\end{tabular}

For post hoc treatment of means, Tukey (a) ${ }^{9}$ was decided upon. It is less strict (more significant differences) than Scheffe but more strict than Newman-Keuls, Duncan or Tukey (b) ${ }^{10}$ procedures in respect to Type I errors (rejection of difference where such difference exists).

In determining the significance of the responses to question 15 through question 19, dealing with attitudes toward the care of foster children, a (two-tailed test) was used to determine the significance

${ }^{9}$ Ibid. , pp. $46-104 . \quad 10$ Ibid. 
of a percentage. Two formulas were used. The first was for question 15 which treated the entire sample. ${ }^{11}$

$$
Z=\frac{P_{1}-P_{2}}{\sqrt{\frac{P u Q u}{N_{1}}+\frac{P u_{2} Q_{2}}{N_{2}}}}
$$

The other formula used for questions 16 through 19 takes into account the smaller observed difference between the percentages because of the elimination of the respondents who answered no to question $15 .^{12}$

$$
\mathrm{Z}=\frac{\mathrm{P}_{1}-\mathrm{P}_{2}}{\sqrt{\mathrm{PuQu}} \sqrt{\frac{\mathrm{N}_{1}+\mathrm{N}_{2}}{\mathrm{~N}_{1} \mathrm{~N}_{2}}}}
$$

The table for the normal curve functions was used for determining the significance of $\mathrm{Z}$ with the critical level set at . 01 .

${ }^{11}$ Blalock, pp. 176-9. 12 Ibid., pp. 170-1. 


\section{CHAPTER III}

\section{RESULTS OF THE STUDY}

Results from the interview data divide into three broad groupings. One group of findings relates to the population sample characteristics. The second group is the frequency of favorable and unfavorable responses to the care of foster children with and without handicaps. The third group has to do with the relationship of the demographic variables, income, education and age in relation to the care of foster children.

\section{CHARACTERISTICS OF THE POPULATION SAMPLE}

A description of the population samples indicates that there are some significant factors indicating a relatively, stable population. For example, approximately 62 per cent of those individuals interviewed have lived in Portland for 20 years or more, and 72 per cent of the respondents are married. Over half the sample population was between the ages of 20 and 40 ; however, over 25 per cent of the population was 65 years of age and older. Another indication of the stability of the population is that 36 per cent of the sample have maintained the same level of income during the past three years. 
Most of the respondents indicated they are able to live within their income, and 45 per cent of the sample currently are buying their own homes. The majority of the respondents pay from \$76-129 for rent or mortgage.

Twenty-five per cent have an annual income of less than $\$ 5,000$, and 45 per cent of the same have incomes that fall within the $\$ 5,000-10,000$ range. It was also discovered that a fairly large group, approximately 19 per cent, had an annual income of $\$ 4,000$. Although 65 per cent of the sample have held their present jobs for four years or more, another 8 per cent have held their present jobs for only six months.

Sixty-eight per cent have a high school education or better. Although only about 25 per cent are involved in community activities, approximately 65 per cent indicated they are members of a church or synagogue and attend religious services on a fairly regular basis.

The average resident within the survey area, based upon the median characteristics of the population sample, can be described as 43 years of age, married and having at least a high school education with an indication of relatively stable employment within the past four years. The median income of the residents is approximately $\$ 7,600$ per year. 
Attitudes Toward Foster Children

With and Without Handicap

Attitudes toward foster children are covered by questions 15

through 19 and Hypotheses V through IX. Findings will be presented using the hypotheses as the basis for discussion.

Hypothesis V states that the majority of respondents "are more likely not to be willing to take care of foster children." Below are the results of question 15:

TABLE II

WILLINGNESS TO TAKE CARE OF FOSTER CHILDREN

\begin{tabular}{lcc}
\hline \hline Responses & Number* & Per cent \\
\hline Yes (+ Maybe) & 192 & 38 \\
No & 465 & 62 \\
\hline
\end{tabular}

$$
Z=6.6666 * * *
$$

*Not all respondents answered question 15 . Those that refused or where the interviewer failed to enter the answer were entered as "no response." The missing 5 per cent is in this latter category.

*** Significant at the .001 level.

The findings confirm Hypothesis $\mathrm{V}$ and are highly significant. Respondents are significantly more negatively disposed toward care of foster children. 
Hypothesis VI states: "As the age of foster children increases individuals (respondents) are less willing to take care of them." Below are the results of question 16:

TABLE III

AGE OF FOSTER CHILD MOST WILLING TO ACCEPT

\begin{tabular}{ccc}
\hline Age & Number & Per cent \\
\hline $0-2$ years & 59 & 23 \\
$3-5$ & 81 & 31 \\
$6-9$ & 46 & 18 \\
$10-12$ & 18 & 7 \\
$13-15$ & 13 & 5 \\
$16-18$ & 0 & 0 \\
\hline $0-12$ & 35 & 13 \\
$13-18$ & 9 & 3 \\
\hline
\end{tabular}

Though no significant tests were made on this data because of the number of comparisons of means to be made, the trend of the data is unmistakable.

From an age range of birth to five years of age, almost 18 per cent of the respondents expressed a willingness to take care of foster children in this age bracket. From age 6 through 18, only 9. 5 per cent expressed such willingness. Not a single respondent expressed a specific interest in accepting a child between the ages of 16 and 18, although 1.14 per cent indicated a willingness to accept a child between the ages of 13 and 18. As a preference range, there 
are no respondents specifically interested in the 16 through 18 yearold foster child.

It is equally apparent that the $0-12$ age $r$ ange $(4.44)$ is a far more popular range for foster placement than the 13-18 age range (1. 14).

The trend of the data is in the direction predicted by: Hypothesis VI. Therefore, this hypothesis is confirmed.

Hypothesis VII states "Individuals are less willing to take-care of foster children with a noticeable physical disability than children without a noticeable physical disability." Below are the results of question 17:

TABLE IV

WILLINGNESS TO CARE FOR A FOSTER CHILD WITH A NOTICEABLE PHYSICAL DISABILITY

\begin{tabular}{lcc}
\hline Responses & Number & Per cent \\
\hline Yes (+ Maybe) & 248 & 86 \\
No & 41 & 14 \\
\hline & $Z=-9.9073$ &
\end{tabular}

For a two-tailed test of significance $\mathrm{Z}$ of -9.9073 is significant well beyond the .001 level.

The percentage of those responding affirmatively to a willing ness to care for a foster child who also respond favorably to 
question 17 is significantly in the favorable direction. Therefore, Hypothesis VII is not confirmed. The slightly larger number of respondents to question $17(+3)$ than those who answered yes or maybe to question 15 is due to the interviewer's failure to precisely carry out the interviewing instructions. This is a very small margin of error.

Hypothesis VIII states "Individuals are less willing to take care of foster children with relatively minor emotional problems than for children without minor emotional problems." Below are the results of question 18:

TABLE V

WILLINGNESS TO CARE FOR A FOSTER CHILD WITH RELATIVELY MINOR EMOTIONAL PROBLEMS

\begin{tabular}{lcc}
\hline \hline Responses & Number & Per cent \\
\hline Yes (+. Maybe) & 231 & 79 \\
No & 60 & 21 \\
\hline
\end{tabular}

$$
Z=-8.6809
$$

A Z of -8.6809 for a two-tailed test is significant beyond the .001 level. The 79 per cent of respondents answering favorably to both questions 15 and 17 is in the direction contrary to that predicted by Hypothesis VIII; therefore, this hypothesis is not confirmed. 
Hypothesis IX states "Individuals are less willing to take care of foster children who are retarded than for children who are not retarded." Below are the results of question 19:

TABLE VI

WILLINGNESS TO CARE FOR A FOSTER CHILD WHO IS RETARDED

\begin{tabular}{ccc}
\hline Responses & Number & Per cent \\
\hline Yes (+ Maybe) & 188 & 63.94 \\
No & 106 & 36.05 \\
\hline
\end{tabular}

$$
Z=-5.9466
$$

The $\mathrm{Z}$ of -5.9466 is significant beyond the .001 level. The 64 per cent responding favorably to this question of those who responded favorably to question 15 is in the direction opposite to that predicted by Hypothesis IX. Therefore, Hypothesis IX is not confirmed.

Relation of Demographic Variables to Attitude Toward Care of Foster Children

Hypotheses I through IV are concerned with the relatedness of the demographic and socio-economic factors, income, education and age, through the willingness or unwillingness to care for a foster child.

Hypothesis I states "Demographic factors of income, education 
and age are related to an individual's willingness to care for foster children."

TABLE VII

ATTITUDES TOWARD CARE OF FOSTER CHILDREN

ACCORDING TO INCOME (NUMBERS)

\begin{tabular}{|c|c|c|c|c|}
\hline Income & Yes & Maybe & $\begin{array}{c}\text { Yes + } \\
\text { Maybe }\end{array}$ & No \\
\hline$\$ 20,000$ plus & 2 & 2 & 4 & 15 \\
\hline 15,000 to 19,999 & 12 & 5 & 17 & 19 \\
\hline 10,000 to 14,999 & 34 & 31 & 65 & 93 \\
\hline 7,000 to 9,999 & 65 & 26 & 91 & 101 \\
\hline 5,000 to 6,999 & 28 & 13 & 41 & 63 \\
\hline 4,000 to 4,999 & 16 & 3 & 19 & 23 \\
\hline 3,000 to 3,999 & 8 & 3 & 11 & 28 \\
\hline Under 3,000 & 14 & 2 & 16 & 76 \\
\hline
\end{tabular}

TABLE VIII

SUMMARY OF ANALYSIS OF VARIANCE

INCOME TO ATTITUDE TOWARD

CARE OF FOSTER CHILDREN

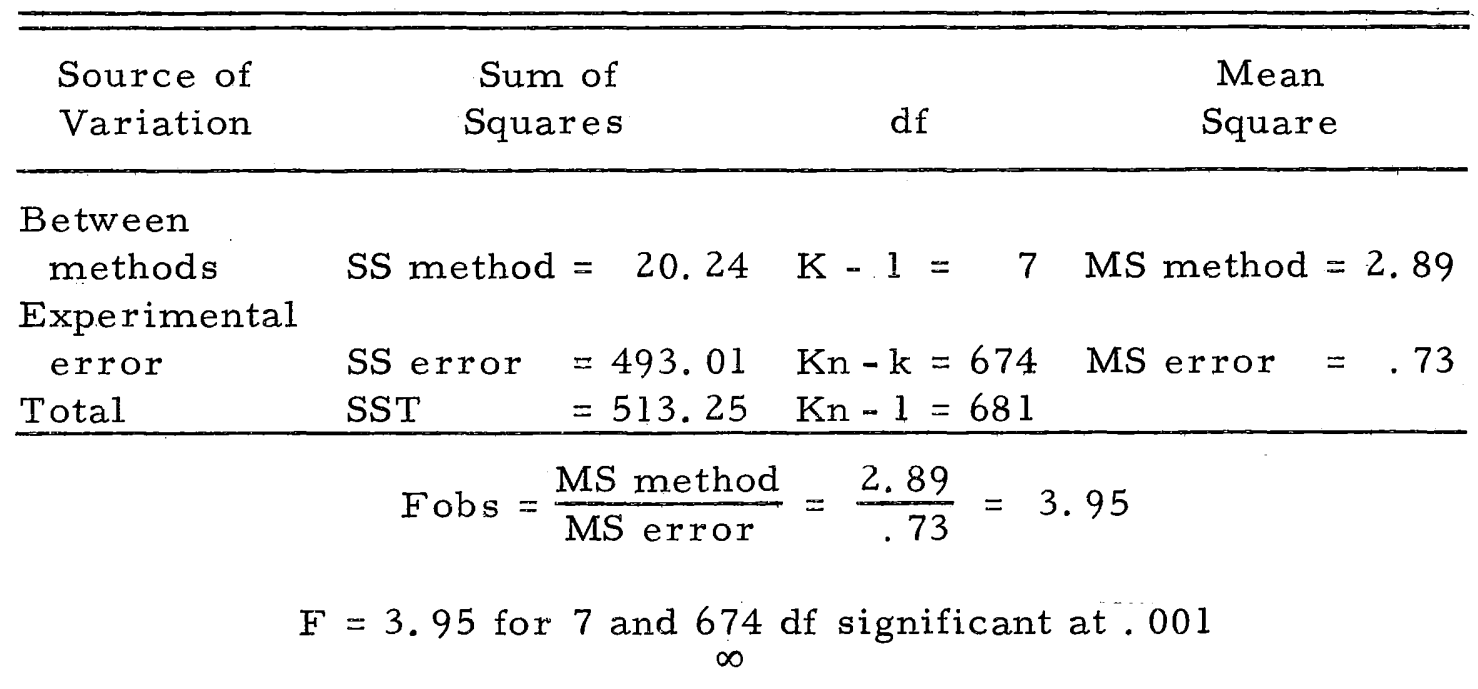


The $F$ of 3.95 for income to attitude is highly significant beyond the .001 critical level.

Age to attitude is detailed in Tables IX and $\mathrm{X}$.

TABLE IX

ATTITUDES TOWARD CARE OF FOSTER CHILDREN ACCORDING TO AGE OF RESPONDENT

(NUMBERS)

\begin{tabular}{lccc}
\hline Age & Yes & Maybe & No \\
\hline Under 20 years & 10 & 4 & 10 \\
20 to 29 & 85 & 31 & 69 \\
30 to 39 & 31 & 21 & 67 \\
40 to 49 & 33 & 22 & 71 \\
50 to 59 & 16 & 8 & 74 \\
60 plus & 17 & 8 & 174 \\
\hline
\end{tabular}


TABLE X

SUMMARY OF ANALYSIS OF VARIANCE

AGE TO ATTITUDE TOWARD CARE

OF FOSTER CHILDREN

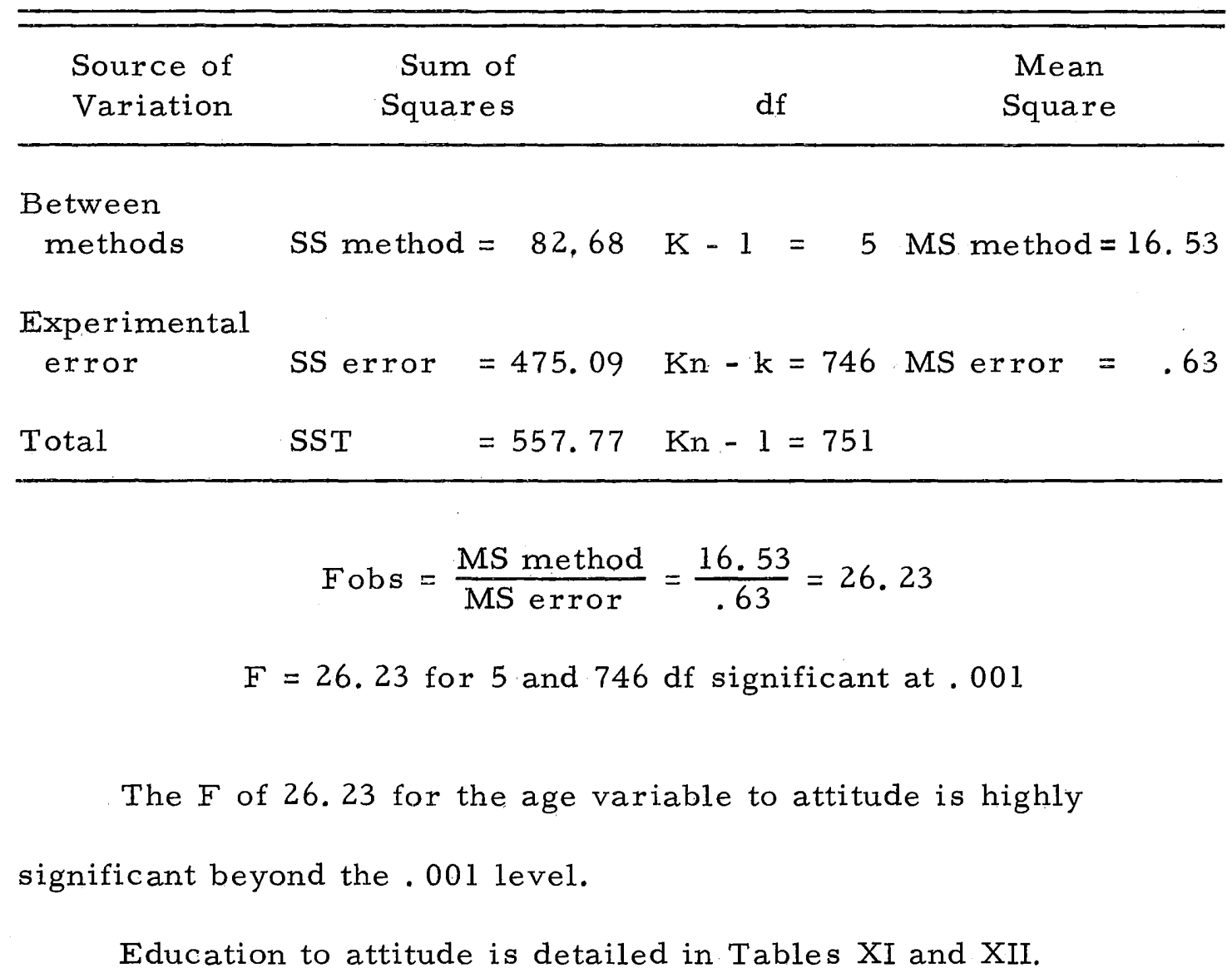


TABLE XI

ATTITUDE TOWARD CARE OF FOSTER CHILDREN ACCORDING TO EDUCATIONAL LEVEL OF RESPONDENT (NUMBERS)

\begin{tabular}{lrrr}
\hline \multicolumn{1}{c}{ Years of Education } & Yes & Maybe & No \\
\hline 5 or less & 1 & 1 & 6 \\
6 to 8 & 11 & 3 & 34 \\
9 to 11 & 20 & 5 & 71 \\
High school graduate & 74 & 39 & 171 \\
Trade or Beauty. School & 19 & 7 & 42 \\
Some college & 49 & 8 & 87 \\
Bachelor's degree & 7 & 6 & 23 \\
Graduate training & 8 & & 21 \\
\hline
\end{tabular}

TABLE XII

SUMMARY OF ANALYSIS OF VARIANCE

EDUCATION TO ATTITUDE TOWARD

CARE OF FOSTER CHILDREN

\begin{tabular}{lccc}
\hline $\begin{array}{c}\text { Source of } \\
\text { Variation }\end{array}$ & $\begin{array}{c}\text { Sum of } \\
\text { Squares }\end{array}$ & df & $\begin{array}{c}\text { Mean } \\
\text { Square }\end{array}$ \\
\hline $\begin{array}{l}\text { Between } \\
\text { methods }\end{array}$ & SS method $=11.67$ & $\mathrm{~K}-1=7$ & MS method $=1.66$ \\
$\begin{array}{l}\text { Experimental } \\
\text { error }\end{array}$ & SS error $=684.73$ & $\mathrm{Kn}-\mathrm{k}=729 \quad \mathrm{MS}$ error $=.93$ \\
$\begin{array}{l}\text { Total } \\
\text { SST }\end{array}=696.40$ & $\mathrm{Kn}-1=735$ & \\
\hline
\end{tabular}

Fobs $=\frac{\text { MS method }}{\text { MS error }}=\frac{1.66}{.93}=1.78$

$F=1.78$ for 7 and $729 \mathrm{df}$ significant at .10 
The $F$ of 1.78 of the education variable to attitude is not significant at the . 01 level.

On the basis that income and age are significantly related to attitude toward care of foster children beyond the .001 level Hypothesis I is confirmed.

Hypotheses IIa and IIb state that responses to the income question will show a significant relationship to the willingness to take care of foster children. Hypothesis IIa states "As income increases there will be less of a tendency on the part of individuals to express willingness to care for foster children." Hypothesis IIb states "The inverse of IIa is that individuals at low income levels (below the $\$ 6,000$ range) will indicate a greater willingness to care for foster children than individuals at any other income level.

Table XIII data relate to the proof of Hypotheses IIa and IIb.

Groups 1, 7 and 8 in Table XIII, the highest and lowest income groups, show a significant tendency to score more in a "no" direction in stating their willingness to accept a foster child. Groups 2 through 6, which represent an income range from $\$ 20,000$ to $\$ 4,000$, differ significantly from the former three groupings in their tendency to indicate a willingness to care for a foster child.

Groups 1, 7 and 8 have the highest mean scores, 1.68, 2. 51 and 2.67 respectively, which almost in every: instance differs significantly from groups 2 through 7 . The exception is group 3 
TABLE XIII

COMPARISON OF MEANS FOR INCOME TO ATTITUDE

\begin{tabular}{|c|c|c|c|c|c|c|c|c|}
\hline & 1 & 2 & 3 & 4 & 5 & 6 & 7 & 8 \\
\hline $\mathrm{X}$ & 2.68 & 2. 19 & 2.37 & 2. 18 & 2.33 & 2.16 & 2.51 & 2.67 \\
\hline 2. 68 & -- & 0.49 & 0.31 & 0.50 & 0.35 & 0.52 & 0.17 & 0.01 \\
\hline 2.19 & & -- & 0.18 & 0.01 & 0.14 & 0.03 & 0.32 & 0.48 \\
\hline 2.37 & & & -- & 0.19 & 0.04 & 0.21 & 0.14 & 0.30 \\
\hline 2. 18 & & & & -- & 0.15 & 0.02 & 0.33 & 0.49 \\
\hline 2.33 & & & & & -- & 0.17 & 0.18 & 0.31 \\
\hline 2.16 & & & & & & -- & 0.35 & 0.51 \\
\hline 2. 51 & & & & & & & -- & 0.16 \\
\hline 2.67 & & & & & & & & $\ldots$ \\
\hline
\end{tabular}

$\mathrm{K}=$ number of $\mathrm{groups}=8$

$\mathrm{V}=\mathrm{D}$ of $\mathrm{W}=674$

$9\left(8_{i}\right) .01=4.99$

$\mathrm{Sp}^{2}=0.83$

$\mathrm{Sp}=.85$

Critical level $=\frac{9 \mathrm{Sp}}{\mathrm{N}}=\frac{(4.99)(.85)}{682}=\frac{4.24}{26.1}=0.16$ 
with a mean of 2.37 .

The income data trend suggests that with an increase in the size of the sample, group 3 would follow the data trend.

Therefore, on the basis of the comparison of means using Tukey(a), Hypothesis IIa is not confirmed except for the highest income category. Hypothesis IIb is also not confirmed. The tendency is for the mid-range of income, a broad range, to show a significant relationship to an attitude of acceptance of care for foster children.

Hypothesis IIIa states "As education increases, there will be less of a tendency on the part of individuals to express willingness to care for foster children."

Hypothesis IIIb states "The inverse of IIIa is that individuals with less than a high school education will indicate a greater willingness to care for foster children than individuals with more than a high school education."

The $F$ of 1.78 is not significant at the .10 level. An inspection of means is as follows:

TABLE XIV

MEANS FOR EDUCATION GROUPINGS

\begin{tabular}{ccccccccc}
\hline \hline 1 & 2 & 3 & 4 & 5 & 6 & 7 & 8 \\
\hline 2.50 & 2.41 & 2.47 & 2.20 & 2.25 & 2.08 & 2.21 & 2.20 \\
\hline
\end{tabular}


Table XIV indicates that there is no discernible trend for educational groupings to relate significantly to attitude toward care of foster children in the predicted direction. Therefore, Hypotheses IIIa and IIIb are not confirmed. Education is broadly represented amongst groups favorably and unfavorably disposed toward care of foster children.

Hypothesis IV states that "Middle-age respondents between the ages of 35 to 50 show a greater tendency to care for foster children than any other age grouping."

Table XV, using Tukey(a) formula, compares means for age groupings.

The mean tends significantly toward the "no" scale of the answer to question 15 as age increases. From a mean of 2.0 for the under 20 age range and 1.91 for the 20 to 29 age range, the means increase in almost linear fashion. All comparisons are significant except for Means 1 and 2 and Means 3 and 4. The data show a significant trend inverse to Hypothesis IV which is not confirmed. The inverse of this hypothesis shows as age decreases "favorableness" to foster care increases and there also is a linear relationship between age and expressed attitude. It also shows that as age increases the tendency toward expressed unfavorableness toward care of foster children increases in a linear fashion. 
TABLE XV

COMPARISON OF MEANS FOR AGE TO

ATTITUDE USING TUKEY (a)

\begin{tabular}{|c|c|c|c|c|c|c|}
\hline & 1 & 2 & 3 & 4 & 5 & 6 \\
\hline $\mathrm{X}$ & 2.00 & 1.91 & 2.30 & 2. 30 & 2.59 & 2.78 \\
\hline 2.00 & -- & $0.09^{\mathrm{ns}}$ & 0.30 & 0.30 & 0.59 & 0.78 \\
\hline 1.91 & & -- & 0.39 & 0.39 & 0.68 & 0.87 \\
\hline 2.30 & & & -- & $0.00^{\mathrm{ns}}$ & 0.29 & 0.48 \\
\hline 2.30 & & & & -- & 0.25 & 0.48 \\
\hline 2. 59 & & & & & -- & 0.19 \\
\hline 2.78 & & & & & & -- \\
\hline
\end{tabular}

$\mathrm{K}=$ number of groups $=6$

$V=D f$ of $W=746$

$9(6) .01=4.76$

$\mathrm{Sp}^{2}=0.63$

$\mathrm{Sp}=.8$

Critical level $=\frac{9 \mathrm{Sp}}{\mathrm{N}}=\frac{(4.76)(.8)}{751}=\frac{3.81}{27.4}=0.13$ 


\section{DISCUSSION OF FINDINGS}

Attitudinal, demographic and socio-economic variables as found in this and other studies are significantly related to who are or who become foster parents. Apart from this generalization, there are apparent differences between the outcomes of this study and what has been found in the literature.

The major difference has to do with the relationship of demographic and socio-economic factors to expressed willingness to care for foster children. In terms of who actually is or who becomes foster parents, the outcomes of this study point to a much broader range of income, age and educational groupings who expressing willingness to become foster parents than expected from the literature. As noted earlier, most studies have described the predominant foster parent type as middle-aged with a stabilized style of family life, tending toward minimum income and education.

Studies referred to in the literature are based on samples of active foster parents. It can be assumed that individuals who are foster parents would have expressed a willingness to care for foster children prior to actual foster parenthood. 
The problem then is to explain the differences as well as the similarities in results of the present study and the published reports on foster parent characteristics.

One supposition on the basis of who is or who is reported to be foster parents is that the population from which the foster parent group is drawn has primarily the same characteristics as those foster parent characteristics reported in the literature. 1

Another possible as sumption is that the population from which the actual foster parent is drawn is much more broadly constituted demographically and socio-economically, but that a selective factor operates to narrow the social and economic range of those who are foster parents.

A third alternative is that the sampling procedures in the present study have introduced population biases which do not reflect the characteristics of those who are willing to care for foster children, If the population sample of this study, is biased, then this study neither confirms nor disaffirms previous reported findings on foster parent characteristics.

There are then four questions that arise in connection with the

${ }^{1}$ The majority of the literature concerns itself with those who are foster parents rather than those who express willingness to be but not as yet are foster parents. This study samples responses and characteristics of those who express a willingness to become foster parents but the majority of whom are not foster parents. 
interpretation of the results. They are as follows:

1. What is the relationship of expressed willingness to care for foster children to being actual foster parents? That is, how highly correlated is expressed willingness to actual foster parenthood if such correlational statements are available?

2. How representative of the S. E. Portland area population is the present study's population sample?

3. What are the characteristics of the population of potential (willing) foster parents from which actual foster parents are drawn?

4. Does the selection and recruitment of foster parents result in a biased sampling of individuals who are willing to care for foster children?

\section{EXPRESSED WILLINGNESS VERSUS ACTUAL FOSTER PARENT}

Few, if any, studies have been done on this subject. In political surveys, the undecided group, in terms of voting behavior, is considered in the "no" category. It is difficult to generalize from studies in other fields. For example, intuitively one would see the "maybe" respondent as approachable and recruitable. The same might have been said of the individual vote on political is sues from a common sense point of view.

A researchable question is how many of those individuals who 
indicated willingness to care for foster children would actually accept such a responsibility if there were no other criteria for foster care than expressed willingness? Allowing for this freedom of choice, there is presently no researched answer to this question.

\section{REPRESENTATIVENESS OF THE SAMPLE}

The three demographic variables of income, age and education are as good an index of demographic characteristics as any other set of indices. Income and education alone are most frequently and generally used as Southeast survey indicators.

Population characteristics of this sample differ markedly from the 1960 census data for the 32 census tracts of the S. E. catchment area. These comparisons must take into account the change in population characteristics over the past ten year period.

In respect to income, the present income breakdown shows a much higher median income than ten years ago (Table XVI).

The inflationary and income spiraling trend over the past ten years, and especially the past two years, supports the survey data of an income increase period. The difference in median income of approximately $\$ 1,700$ represents a 28 per cent rise in median income for the survey area. 
TABLE XVI

COMPARISON OF INCOME DISTRIBUTION FOR MENTAL HEALTH SURVEY AND 1960 CENSUS FOR

S. E. PORTLAND CATCHMENT AREA

\begin{tabular}{ccc}
\hline Income & 1960 Census $^{1}$ & Present Study \\
\hline Less than $\$ 3,000$ & $15.7 \%$ & $13.9 \%$ \\
$\$ 3,000-6,000$ & 33.2 & 18.7 \\
$\$ 6,000-10,000$ & 37.7 & 34.8 \\
$\$ 10,000$ and over & 13.7 & 29.2 \\
Median Income & $\$ 6,100$ & $\$ 7,800$ \\
\hline
\end{tabular}

${ }^{1}$ Metropolitan Planning Commission, Report of the Commission, Portland Metropolitan Area: Population and Housing (1965).

The S. E. catchment area is becoming a place of aging residents or younger families with median incomes who tend to inhabit the new multiplexes which are the major type of new housing construction in the S. E. catchment area, ${ }^{2}$

Another interesting population trend is the stability of the lowest income groups. The southeast Portland area contains five neighborhoods which fall under the poverty neighborhood definition of O.E. O. These neighborhoods are also receiving areas for the

2 Metropolitan Planning Commission, Report of the Commission, Portland-Vancouver SMSA Housing Analysis, 1960-1980. (1965). 
poor white immigrant population. ${ }^{3}$ The EOA study conducted from June, 1968 to August, 1968 showed 20 per cent of the respondents with income below $\$ 3,000$ in these neighborhoods. There are, therefore, indications that the income characteristics and trend of this sample are supported by the economic trends and findings in another study.

It is difficult to make comparisons between this study's sample regarding age and the census data. One reason is that the survey eliminates any but heads of household, spouse or responsible adult over 18 as respondent. This truncates the total population base by eliminating most of the adolescent age group and all of the younger children.

In this study, the age distribution peaks at 20 to 29 and is skewed in the positive direction with the very old (70-80) and the teen married group being significantly smaller.

The population distribution is what could be expected if it conforms to the relative age distribution for those who would be considered heads of households. The latter would in general not be working and would be predominantly female who would be at home during the mornings and afternoons.

${ }^{3}$ M. S. Levine, William H. Banaka and Alan Frankel, A Study and Evaluation of Portland EOA Programs, Report to Portland Action Together Committee, Portland, Oregon, December, 1968, p. 16. 
The above -65 group for the study in the 1960 census stood at 14. 1 per cent of the southeast area population. In this study, the population percentage for the 65 and over range is approximately 16.3 per cent. ${ }^{4}$ This is reasonably close to the 1960 census since those who remain in S. E. Portland would be the older established citizens on limited incomes who have resided in the area for at least 20 years.

Age, if not conclusively representative of the population sample, does show by its distribution a tendency toward representativeness of the general population.

Regarding education factors, the upward trend as in income is again noticeable. Table XVII shows the results in numbers and percentages of the distribution of the respondents on the basis of education for this study and for the 1960 census.

There are marked differences in the more educated direction for the present study period. This more-educated trend is also true of the national trend. A recent study emphasizes this trend. ${ }^{5}$

${ }^{4}$ For this survey, age was grouped by deciles beginning with below 20, then 20 to 29 , etc. To obtain the 65 and above grouping, the 60 to 69 age count for this study, was divided in half, allowing for an estimate of the 65 and over group.

${ }^{5}$ C. G. Benjamin, "Book Publishing's Hidden Bonanza," Saturday Review of Literature, February 18, 1970, p. 82. 
TABLE XVII

SURVEY EDUCATIONAL LEVEL COMPARED TO 1960 CENSUS

\begin{tabular}{lrcc}
\hline \multicolumn{1}{c}{$\begin{array}{c}\text { Years of } \\
\text { Education }\end{array}$} & Number & Per cent & $\begin{array}{c}1960 \\
\text { Census }\end{array}$ \\
\hline or less & 8 & 1.02 & \\
6 to 8 & 56 & 7.12 & 15.62 \\
9 to 11 & 100 & 21.71 & 17.52 \\
High School Graduate & 288 & 36.59 & 25.17 \\
Trade or Beauty School & 75 & 9.53 & --5 \\
Some college & 172 & 21.86 & 11.03 \\
Bachelor's degree & 39 & 4.96 & 7.38 \\
Graduate training & 35 & 4.45 & --- \\
\hline
\end{tabular}

In comparing 1959 with 1969 there were 8.3 million college graduates and in 1969 there were 13.8 million college graduates. This is an. increase of more than 60 per cent in the number of college graduates during the ten-year period. This is striking even considering population increases in that same ten-year period. The S. E. Portland study depicts the trend toward more education with a nearly 70 per cent increase in high school graduates.

The population sample drawn for this study departs significantly from the 1960 census tract data for this area. The differences in population characteristics, primarily upswings in income and education, mirror national trends for these indices. The age index conforms to expected age distribution for heads of households or spouses who would be available for interviews during those hours 
in which the majority ( 75 per cent) of the interviews were conducted. In addition, regarding the age factor, the age distribution predominantly samples the mid-range, that is, 20 to 60 which reflects the age distribution in the population in general.

\section{CHARACTERISTICS OF POTENTIAL FOSTER PARENTS}

The demographic socio-economic information compiled in this study indicates a substantially larger group of individuals expressing willingness to accept foster children than is demonstrated by current or most recent research data.

As stated earlier, it can be assumed that present foster placement agencies are not utilizing as broadly a based population as profiled in this study. The following tablecompares a profile of a foster parent as described in most of the literature to a profile of a respondent who expressed willingness to accept a foster child in this study:

TABLE XVIII

PROFILE COMPARISONS

\begin{tabular}{lccc}
\hline \multicolumn{1}{c}{ Source } & Income & Age & Education \\
\hline Literature & $\$ 4,000-6,000$ & $35-40$ & Non-high school graduates \\
$\begin{array}{l}\text { Survey } \\
\text { Respondents }\end{array}$ & $\$ 4,000-19,000$ & $20-29$ & $\begin{array}{l}\text { Approximately 64 per cent } \\
\text { are high school graduates }\end{array}$ \\
\hline
\end{tabular}


There have been marked changes in local and national social and economic conditions. It is possible that along with income and education such changes have occurred in the social and economic characteristics of those who are willing to care for foster children.

\section{SELECTION OF FOSTER PARENTS}

Expressed willingness to care for foster children differs from actual care. Actual care, however, implies a willingness to care for foster children. Because of this factor, it is assumed that the population drawn upon for foster care as reported in the literature is either (1) very similar in characteristics between those who actually care for foster children and those who express a willingness to accept a foster child; (2) representative of a particular trend or bias in the community in which a particular study was completed; or (3) representative of a peculiarity of recruitment and selection procedures by placement agencies. There is little in the literature to provide much substantiation for the first two as sumptions; however, there is some support for the assumption regarding agency peculiarities of recruitment and selection criteria.

Many authors indicate a lack of community knowledge regarding the function of foster parents as one of the key elements in the 
limited availability of foster homes. ${ }^{6}$ One study showed that approximately 43 per cent of the sample families interviewed had neither heard, read nor seen any publicity about an agency's need for foster care. ${ }^{7}$ A similar study by Simsarian reported that 100 per cent of a sample she interviewed were almost totally uninformed about community foster care progress. 8

Even though lack of public knowledge about foster parenthood programs appears to handicap recruitment efforts, there is a good deal of evidence that only a small minority of foster parent applicants actually are accepted or used. For example, many foster parent applicants tend to withdraw their applications during an agency's extensive home study process. In addition, numerous candidates are rejected by agencies on the basis of inadequate housing, psychological problems and lack of adequate financial compensation.9

The response of expressed.willingness to care for a handicapped foster child reflects a more generalized, favorable response

${ }^{6}$ Glassberg, p. 456.

7 Kenneth Dick, "What People Think About Foster Care," Children, VIII (1961), 48-9.

${ }^{8}$ Francis P. Simsarian, "Foster Care Possibilities in a Suburban Community," Children, XI (1964), 101.

${ }^{9}$ Taylor and Starr, pp. 372-3. 
to foster care evidenced in this study than is reported in the literature. Tables IV through VI in Chapter III on findings reveal that a significant percentage of those who state they are willing to take care of a foster child are also willing to extend such care to a handicapped child.

The expressed readiness to care for a normal and handicapped child may be part of a response attitude or set which is generalized; namely, that a person saying "yes" to question 15, will say "yes" to questions 17 through 19. This "set" explanation holds for the physically and minor emotionally handicapped but does not maintain the same generality of response for the mentally retarded child. For the physically handicapped, 86 per cent of those who responded positively to question 15 , also responded positively to question 17 . For the minor emotional problem child, the proportion was 79 per cent of the question 15 "yes" respondents. The "mentally retarded" ques tion drew a 64 per cent positive response. The variation in response to these three questions, though it reflects a response tendency to express willingness to take care of any child in need, also indicates a discriminating response dependent upon the unique condition or characteristics of the foster placement of a foster child.

There is thus a population of individuals expressing willingness to care for foster children and to a large extent despite physical, minor emotional and intellectually handicapping conditions of 
the child which represents a very broad spectrum of the population.

It appears that recruitment procedures of placement agencies have an influence on who becomes a foster parent contrasted with the potential range of applicants who might express or indicate willingness to take care of foster children. It is reasonable to as sume that the other major findings of this study are related to the se recruitment procedures. 


\section{CHAPTER V}

\section{SUMMARY AND CONCLUSIONS}

Sample survey method and design distinguishes the present study on attitudes toward foster care and related demographic and socio-economic population characteristics from previous studies of foster parent characteristics. The latter were post hoc analyses of actual foster parents.

These differences undoubtedly are a result of the difference in sampling method and the fact that this study was concerned with expressed willingness to care for foster children rather than the characteristics of those who actually are foster parents.

In this study, it was shown that most of the respondents who expressed a willingness to care for foster children fell within the 2029 age range as contrasted with a middle-aged foster parent population as described in the literature. It also discovered, based on the findings of the study, that there is a much broader range of persons willing to accept foster children according to income and education variables than has been indicated in earlier research projects on foster parenthood.

The is sue of whether or not expressed willingness is 
equivalent to, or implies, the commitment to foster parenthood if the opportunity presented itself cannot be answered by the present study, nor are there any answers to it in the literature. It is known that becoming a foster parent is a result of screening and recruitment factors with the implication that those chosen are selected from a range of demographic and socio-economic characteristics that is broader than the social strata that becomes involved in actual foster care.

Random sampling of a population that is geographically defined rather than role defined and using these findings to attempt to shed light on a social need is not the usual approach to analyzing ongoing social work services. Generally the approach is to sample the population involved in existing service to determine the programs' effectiveness and to plan for change or improvement. The literature on foster child care typifies the latter approach.

Sample survey methodology, however, has been part of social service and social work research since the early 1900's; survey technique has been used to identify social need and for program planning. 1

There is a difference of opinion as to how far the researcher

${ }^{1}$ Fred Massarik, "The Survey Method in Social Work: Past, Present, and Potential" in Survey Research in the Social Sciences, ed. by C. Y. Glock (New York: Russell Sage Foundation, 1967), pp. $381-3$. 
can go in interpreting survey results. Moos and Polansky have stated that survey findings are solely descriptive. ${ }^{2}$ Massarik and others argue that survey findings can have far reaching interpretations of need, of service impact and program change and planning. 3

The problems in making generalizations on the basis of survey data either descriptive or interpretative have to do with the soundness of the questionnaire. Was the questionnaire constructed with the notion of testing assumptions in the topical areas being surveyed? Another problem is the skill of the interviewers employed. A third technical point is the sampling method used.

In this survey, the questionnaire was constructed in an attempt to test assumptions about population characteristics of those who use and do not use mental health services. These characteristics include demographic, socio-economic, expressed mental health need and actual mental health needs as measured by selected personality measures that had been standardized on selected but large population samples. 4

The interviewers employed in this survey. were paid, generally middle-aged, and trained for a total of 32 hours. They were

$$
\text { Ibid., p. } 386 . \quad 3 \text { Ibid., pp. 388-97. }
$$

${ }^{4}$ Ego-resiliency subscale of the MMPI, Health Opinion Survey Scale of the Cornell Medical Index, Rotters IE scale, Marlowe Crowne, Social Conformity Scale. 
supervised by an MA sociologist with experience in field survey methods,

Because of the technical preparations in conducting this survey and the fact that the population sample showed characteristics that reflect social and economic changes that have taken place in the last ten years, it is assumed that the findings of this study go beyond mere description of social need and resources.

Obviously more study is needed in this field of foster parenthood. For as in the case of most foster parenthood research, this study tends to raise more questions than offering clear-cut answers. However, accounting for the problems in making generalizations on the basis of survey data either descriptive or interpretative, some assumptions can be made as a result of this study.

It might be assumed, for instance, that the discrepancies between the literature profile of a foster parent and the survey profile of individuals who expressed willingness to accept foster children may be influenced by the fact that agencies have historically relied on the types of individuals described throughout the literature, namely, middle-aged, minimal education and generally fixed minimal incomes. This is alarming insofar as this particular age group and its economic status "is a declining proportion of the population. 15

${ }^{5}$ Taylor and Starr, p. 376. 
Another factor accounting for such discrepancies might be the result of a läck of current (post-1966) research on foster parenthood, including personality as well as demographic information.

The implications of this study are numerous. Many placement agencies undoubtedly: would be forced to as sume additional financial burdens if such agencies were to begin to actively recruit the type of individual profiled in this study who expressed a willingness to care for foster children. Such an effort would require agencies to greatly expand and renovate present supportive services, including better counseling and screening procedures, better consultation programming, improved research techniques and more in-service training for foster parents and applicants.

Evidence uncovered in this study clearly seems to indicate that the segment of the population which is most willing to care for foster children, at least in terms of expressed willingness, is considerably younger, perhaps including some childless couples with little or no parental experience, more mobile and less financially established though not necessarily financially unstable.

Despite the findings which indicate a much broader range of individuals interested in foster parenthood, it is known that considerably more individuals express willingness but actually never become foster parents. In relation to this study, the following assumptions might be considered to ask why this situation occurs: 
1. There is a lack of effective recruitment procedures by agencies.

2. Presentation of survey question regarding the willingness to accept foster children may have coerced certain respondents to answer with an affirmative response.

3. Some individuals who responded affirmatively to accepting foster children would not meet current agency standards.

4. There are inflexible or possibly out-moded agency standards and regulations as they relate to foster parent applicants.

In this study it would have been extremely informative to compare the personality tests that were included in the total sampling questionnaire between actual foster parent respondents, those who expressed willingness and those individuals who demonstrated no interest in accepting foster children. Unfortunately, the deadline for this study would not allow for such comparisons.

Another interesting is sue raised in this study was the apparent reluctance of persons who expressed willingness to accept an older adolescent foster child as contrasted with the desirability of a foster child who would fall within the 0-12 age range. Other information contained in the total survey questionnaire would perhaps indicate the social, cultural and psychological causes for such reluctance.

In conclusion, it would appear that if foster care is to remain a vital social response to dealing with one of the most critical 
problems in child welfare, then further research is needed regarding the findings and some of the questions raised in this study. 


\section{REFERENCES}

Babcock, Charlotte. "Some Psychodynamic Factors in Foster Parenthood--Part I. " Child Welfare, XLIV (1965), 485-93.

Babcock, Charlotte. "Some Psychodynamic Factors in Foster Parenthood--Part II." Child Welfare, XLIV (1965), 570-77.

Benjamin, C. G. "Book Publishing's Hidden Bonanza." Saturday Review of Literature, February 18, 1970, p. 82 .

Blalock, H. M. Social Statistics. New York: McGraw-Hill, 1960.

Bremmer, Robert H. American Philanthropy. Chicago: University of Chicago Press, 1960.

DeFries, Zira; Jenkins, Shirley; and Williams, Ethelyn C. "Foster Care for Disturbed Children--A Nonsentimental View." Child Welfare, XLIV (1965), 73-84.

Dick, Kenneth. "What People Think About Foster Care." Children, VIII (1965), 48-52.

Dinnage, Rosemary, and Pringle, M. L. Kellmer. Foster Home Care Facts and Fallacies. London: Longmans, 1967.

Fanshel, David. Foster Parenthood: A Role Analysis. Minneapolis: University of Minnesota Press, 1966.

Glassberg, Eudice, "Are Foster Homes Hard to Find?" Child Welfare, XLIV (1965), 453-460ff.

Hanson, Morris; Hurwitz, William; and Madow, William. Sample Survey Method and Theory. New York: John Wiley and Sons, 1953.

Levine, M. S. Proposal for Evaluation of Need, Use and Impact of Mental Health Services and Related Resources on Southeast Catchment Area of Portland, Report Oregon State Division of Mental Health, Salem, Oregon, June, 1968. Salem, Oregon: Office of Oregon State Division of Mental Health, 1968. 
Levine, M. S. ; Banaka, William H. ; and Frankel, Alan. A Study and Evaluation of Portland EOA Programs. Report to Portland Action Together Committee, Portland, Oregon, December, 1968. Portland, Oregon: Office of Portland Action Together Committee, 1968.

Massarik, Fred. "The Survey Method in Social Work: Past, Present, and Potential. " Survey Research in the Social Sciences. Edited by C. Y. Glock. New York: Russell Sage Foundation, 1967.

Maas, Henry, and Enger, Richard. Children in Need of Parents. New York: Columbia University Press, 1959.

Metropolitan Planning Commission. Report of the Commission. Portland Metropolitan Area: Population and Housing. Portland, Oregon: 1966.

Metropolitan Planning Commission. Report of the Commission. Portland-Vancouver SMSA Housing Analysis, 1960-1980. Portland, Oregon: 1965.

Rich, Mabel. "Foster Homes for Retarded Children." Child Welfare, XLIV (1965), 392-4.

Simsarian, Francis P. "Foster Care Possibilities in a Suburban Community." Children, XI (1964), 97-102.

Taylor, Delores A., and Starr, Philip. "Fostering Parenting: An Integrative Review of the Literature." Child Welfare, XLIV (1967), 371-84.

Trasler, Gordon. In Place of Parents, London: Routledge and Kegan Paul, 1960.

Winer, B. J. Statistical Principles in Experimental Design. New York: McGraw-Hill, 1962.

Wolins, Martin. Selecting Foster Parents. New York: Columbia University Press, 1963. 